\title{
Structure, Building Envelop and Form integration in Architecture
}

\author{
Shaibu Bala Garba* \\ Qatar University, Qatar
}

*Corresponding author: Shaibu Bala Garba, Department of Architecture and Urban Planning, College of Engineering, Qatar University, P.O. Box 2713, Doha, Qatar.

\section{Introduction}

Contemporary Architecture is witnessing a significant transformation, because of developments in technology that is releasing architects from the use of static forms and historical construction methods, to the use of more dynamic forms that integrate elements of structure, building envelop and form in designs. This paper briefly examines developments in architecture over time, in order to situate and discuss the current emerging trend of integration. The article starts from exploring the history of architecture and the form of buildings in the different eras. It then moves on to discuss the contemporary trend in building form, structure and envelope integration, exploring some of the factors that are drive the trend and discussion of implication for the form of future architecture.

\section{Historical Development of Architecture}

The development of Human civilization has occurred in parallel with that of buildings which cater to the needs of people and their activities. Buildings have evolved to address different types of needs including housing, places of worship, symbolic representation of cultures as well as indicators of level of societal development [1]. From the early stone age period when people lived in caves, shelter development has moved through different stages of development, to the Prehistoric cave with Terra Amata as example, the stone age construction of cities like Catal Huyuk, which embodied the earliest form of urban living, the period of the ancient Near East, when city form and courtyard type house became standardized. The ancient Egyptians, Greek and Roman civilization transformed architecture, introducing both structural and functional complexity, along with formal decoration that elevated the artististic status of architecture. The development of architecture continued during the Early Christian and Byzantine period, when structural complexity assumed a higher dimension in religious buildings such as in Gothic churches and byzantine Mosque. The $20^{\text {th }}$ century saw a radical break with past structural practices in building with the introduction of concrete and steel. Predominantly stone building construction using arches, vaults and beams gave way to reinforced concrete construction and subsequently to steel and glass. The period following the industrial revolution saw the rise of professions and specialization in activities. Architects, Engineers and Builders emerged as dominant disciplines within the construction industry. While Architects specialized in building design with focus on the harmonious integration of function, form and mechanical systems, Civil Engineers evolved with responsibility for the design of the structural systems of buildings [2]. Together, their activities during the period led to phenomenal advances in building design and construction that is visible in both modern and postmodern building, as displayed in works by such architects as Frank Lloyd Write, Mies van Der Rohe, Zaha Hadid and others. The advances were facilitated by their varied vision in the recognition and use of new materials and techniques of construction, along with the ability to think and look for new ways of doing things [2]. Our contemporary era is also witnessing a shift and change in the way buildings are being designed. Development in technology is fundamentally changing the way we design and make buildings. It appears that there is now a better understanding of how buildings work [3]. There are new emerging materials such as fiber reinforced concrete that are enabling architects to experiment with unique forms and structural arrangements that stretch beyond current understanding [4] (Figure 4). Technologies such as Structural analysis software (TEKLA as example), digital Printing, RFID and GPS are fundamentally changing the way we undertake analysis, conceive of, produce and assemble buildings [5,6]. New materials provide for more efficient construction. Printing technologies are enabling factory type assembly of elements, thereby introducing quality standards used in industrial production. Technologies that facilitate location coordinate tagging and mapping are enabling the 
assembly of complex buildings. The following section examines the form and character of the emerging form of buildings from current developments in Architecture and construction.

\section{Structure, Building Envelop and form in Contemporary Architecture}

From the structural point of view, the architectural solution must utilize and exploit the structure to the fullest extent. Currently, new materials, better understanding of different materials and their character is leading to more innovative design that is integrating form, structure and envelope in new ways. This is best expressed in monument constructions such as stadiums, Arenas and hotels, but is also gradually moving down the chain to housing and other forms of building because of advances in digital printing. The character associated with the contemporary trend is closely linked to 3-Dimensional funicular forms associated with tents and synthetic fabrics. Their overall character is one of dynamism and movement, and ability to efficiently provide broad functional spaces within very interesting formal organization. Figures 1-6 below show broad examples of some of unique architectural projects that have exploited this trend. The question is what is driving the trend towards such buildings. Examination of the answer has to point to recent developments in technology, that is enabling creativity beyond what was feasible before These technologies include parametric design, digital printing, advances in pre-casting, location geo-tagging of construction components, along with improvements in modeling and visualization, including the use of virtual reality. What all these building end up communicating, is that we are now approaching a point whereas architects and design professionals, we are not limited or bounded by the tools we have, but rather by our capacity to imagine and create (Figures 1-6).

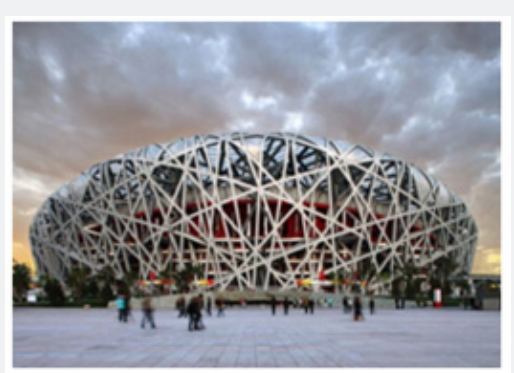

Figure 1: Beinjing National Stadium (Source: Sh.news.fang.com).

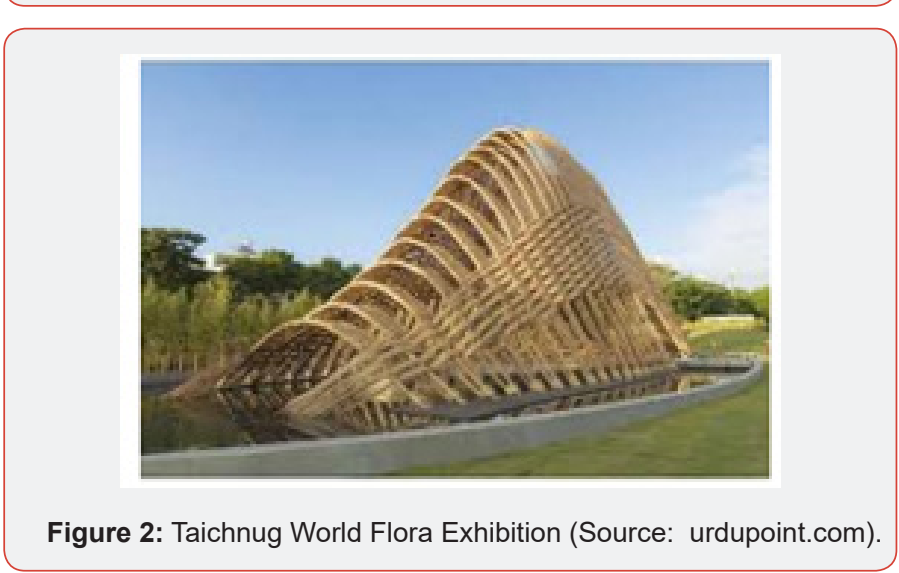

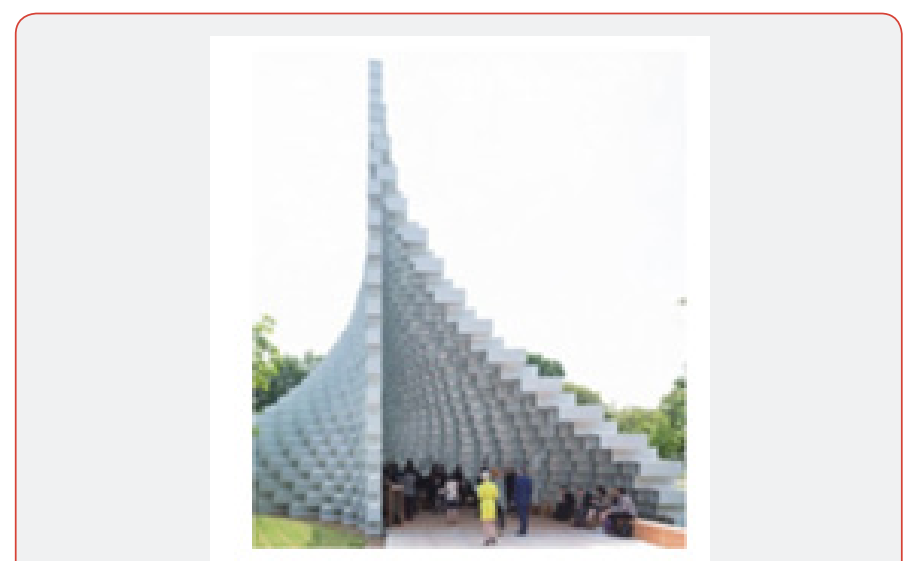

Figure 3: Serpentine Pavillion (Source: Serpentinegalleries.org).

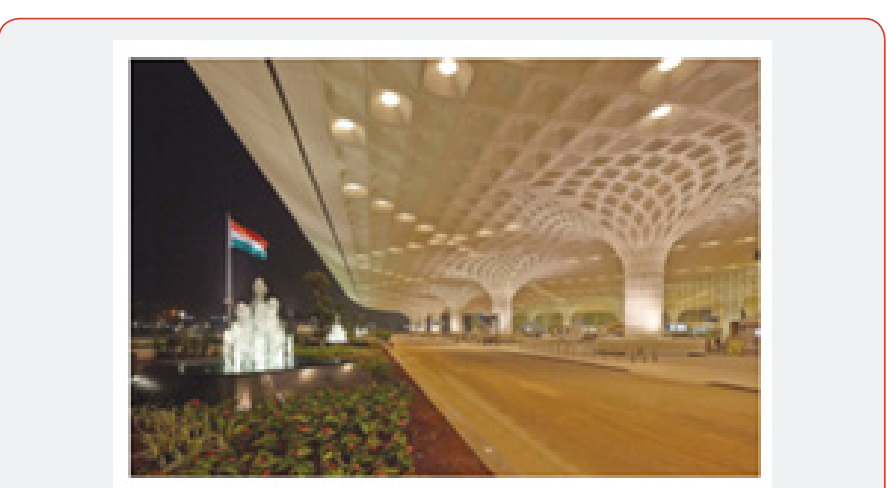

Figure 4: CSMIAAirport India (Source: mgsarchitecture.in).

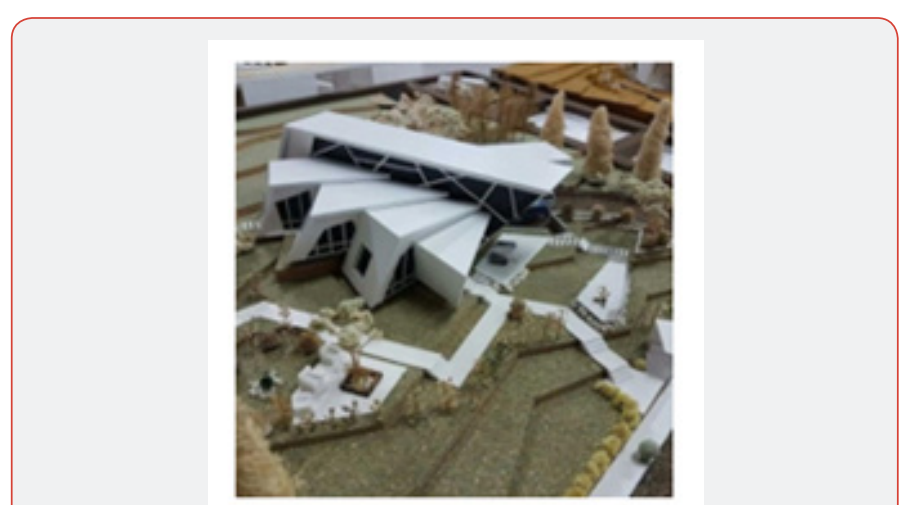

Figure 5: Architecture Project (Source; Pinterest.com/ldianita2o).

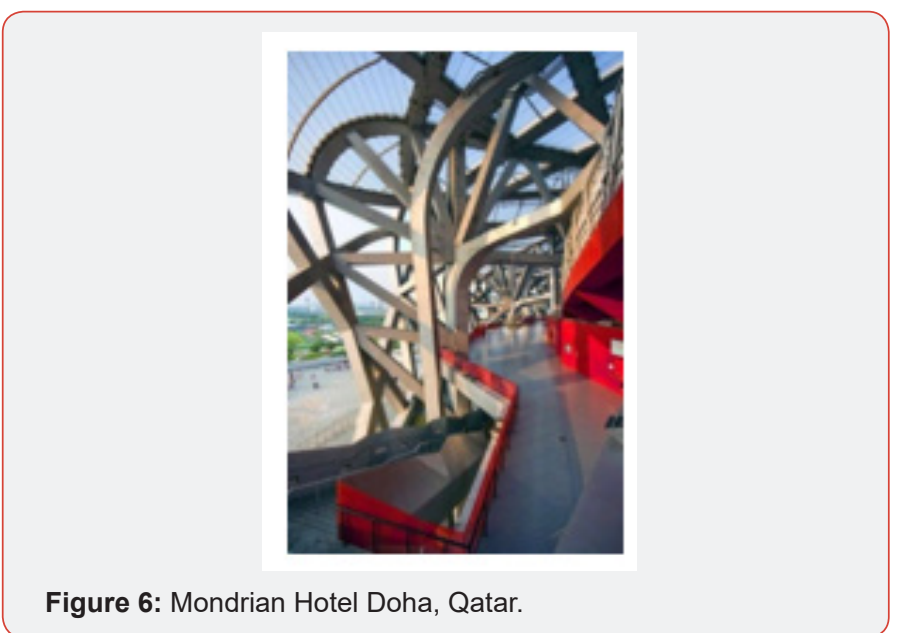

Citation: Shaibu Bala Garba. Structure, Building Envelop and Form integration in Architecture. Cur Trends Civil \& Struct Eng. 4(4): 2020 CTCSE.MS.ID.000595. DOI: 10.33552/CTCSE.2020.04.000595. 


\section{Implication for the future of Construction and Architectural Design}

What implication does the current trend harbor for the construction industry? The future of building industry will likely shift from emphasis on onsite construction which takes time, involves multiple sub-contractors and is generally recognized as inefficient, to an industrial process, whereby designs can be printed and simply assembled on onsite. The engineering of new materials would also reduce the weight of components and facilitate easier transportation and assembly. Components might likely be supplied with pre-installed service elements enabling plug and play. Within the framework of this development, it is going to be likely that there will be consolidation in the building industry. Consolidation, while enabling faster delivery with high levels of quality, may in the end contribute to huge unemployment as the vast number of semiskilled workers that man construction activities become redundant. As part of the change, architects would become flexible and creative in design to produce whatever type of form they want. Emerging tools such as parametric design and Building Information Modeling are already enabling such creativity and leading to unique and more complex forms. The capacity for virtually experience of conceptual buildings will also improve design from both an integration and use perspective. Combination of the design tools with improving capability for the printing and location geo-coding of components will facilitate buildings that are evolving as "what could be" and not "what had to be".

\section{Acknowledgment}

None.

\section{Conflict of Interest}

No conflict of interest.

\section{References}

1. Spirrow K (1995) History of Architecture, Oxford University Press, UK.

2. Aysin S (2001) Integrating Architecture and structural form in Tall Steel Buildings, CTBUH Journal, Spring.

3. Allen E (2005) How Buildings Work; the Natural Order of Architecture (3rd Edn.). Oxford University Press, UK.

4. Yu R, van Onna DV, Spiez P, Yu QL, Browers HJH (2016) Development of Ultra-Light Weight Fiber Reinforced Concrete applying expanded waste glass, pp.690-701.

5. Abdulrahman A, Xing Su, Hubo Cai (2012) A Framework of RFID and GPS for tracking construction site dynamics, Paper presented at Construction Research Congress May 21-23,2012, Lafetatte, Indiana, USA.

6. Izabela H, Anna G, Roman P (2016) 3D printing of building components as the future of sustainable Construction, Procedia Engineering, 151: 292-299. 